Review Article

\title{
An unusual presentation and management of incarcerated Richter's type of Spigelian hernia: a rare case report and review of literature
}

\author{
Prabhu Ravi*, Ramprasad Rajebhosale, Najam Husain
}

Department of General Surgery, Queens Hospital, Burton on Trent, UK

Received: 09 August 2020

Accepted: 16 October 2020

\author{
*Correspondence: \\ Dr. Prabhu Ravi, \\ E-mail: prabhuravi87@yahoo.com
}

Copyright: ( ) the author(s), publisher and licensee Medip Academy. This is an open-access article distributed under the terms of the Creative Commons Attribution Non-Commercial License, which permits unrestricted non-commercial use, distribution, and reproduction in any medium, provided the original work is properly cited.

\begin{abstract}
Spigelian hernias $(\mathrm{SH})$ are one of the rare forms of ventral abdominal hernias which constitutes about $1-2 \%$. SH occurs through the defect in the anterior abdominal wall adjacent to the semilunar line which occurs in the lower abdomen where the posterior sheath is deficient. The usual presentation of SH is a painful mass in mid abdomen above anterior superior iliac spine (ASIS). The diagnosis is made by means of ultrasound and computed tomography (CT). We report 69 years old female who is a known case of Parkinson's disease and on medication presented with 2 days of suddenonset right iliac fossa (RIF) associated with intermittent nausea, vomiting and also abdominal distension. O/E: Abdomen soft, tenderness in RIF with swelling above the line of ASIS. With the diagnosis of lateral abdominal wall hernia we took a CT scan that shows obstructed SH. Immediately she underwent surgery, intra-operative picture shows intraparietal hernia with Richter's type and viable bowel. Abdominal wall is very weak and flimsy with no proper differentiation between the layers. Preperitoneal mesh repair was performed. The post-operative (post op) period was uneventful. Till now there was only 6 type of Richter's SH reported. In this article we discuss a brief knowledge of SH and the management part of SH. We hope that this article will benefit among the surgeons in treating with SH.
\end{abstract}

Keywords: Spigelian hernia, Ventral abdominal hernias, Richter's type of hernia

\section{INTRODUCTION}

$\mathrm{SH}$ is otherwise called as lateral abdominal wall hernia which is a rare type of all ventral hernias. The name was first coined by the 17 th century Belgian anatomist, Adrian van der Spieghel, who first described the semilunar line and on 1764 that it was first reported as a clinical entity by the Flemish anatomist Josef Klinkosh.1 The incidence of this type of hernia usually varied from 0.1 to $2 \% .2$ It occurs frequently in patients between 40 and 70 years of age with predominance in the female with a sex ratio of 1.18: 1.2 It occurs through the slit in anterior abdominal wall in the semilunar line which extends from tip of 9th costal cartilage to the spine of the pubis bone at the lateral edge of rectus muscle inferiorly. Usually it occurs below the umbilicus where there is deficient in posterior rectus sheath. This is usually difficult to diagnosis due to thick abdominal fat.3 Surgery is the only treatment options for all symptomatic patients which constitutes up to $24 \%$ due to the sharp fascial margin around the defect. 4

\section{REVIEW}

Our patient was 69 years female presented with 2 days of sudden-onset right iliac fossa pain radiating to umbilicus with no specific aggravating and relieving factors. She also presented with intermittent nausea and vomiting and constipated for 2 days. No urinary symptoms. No fevers/chills/rigors. She is a known case of Parkinson's disease and currently taking medication and underwent umbilical hernia repair. There is no other medical and surgical history.

On examination, there is a distended lower abdomen with palpable mass in right iliac fossa which is tender to touch and not peritinitic. There was no renal angle tenderness. 
Hernial orifices are free and genital examination was unremarkable. Digital rectal examination shows empty rectum and sphincter tone is normal with no fissure or haemorrhoids.

\section{Investigations and treatment}

Bloods shows elevated inflammatory markers including $\mathrm{C}$ reactive protein (CRP) and white blood cells (WBC) with no drop in haemoglobin. Lactate was 1.2. Preferred diagnostic imaging include abdominal $\mathrm{X}$ ray, Doppler ultrasonogram, computed tomography (CT) and magnetic resonance imaging (MRI). Proximal dilated loops with distal collapse and also transition point will tell us the site of obstruction. The availability of ultrasound scan is limited in out of hours in our trust; $\mathrm{X}$ ray abdomen shows dilated bowel loops with air and gas shadow present which was inconclusive. So the plan to take CT scan was suggested. In our case the CT report shows obstructed spigelian hernia with bowel contents in absence of liver pathology or any other malignancy (Figure 1 and 2).

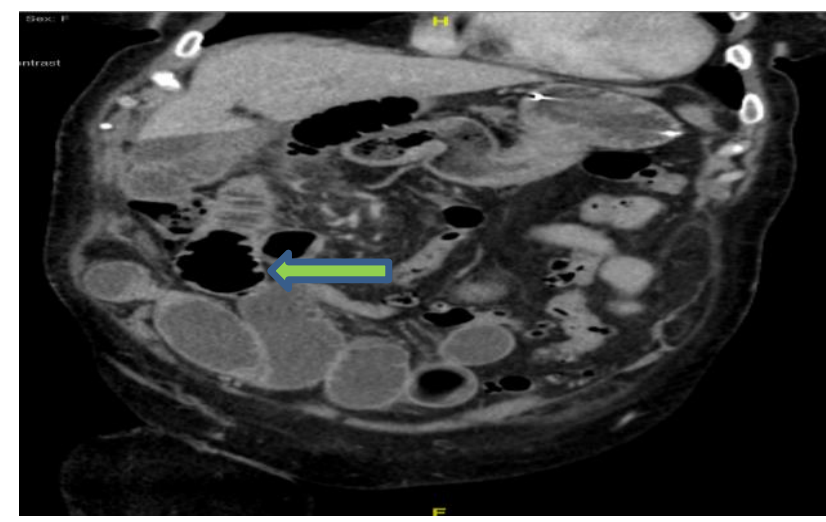

Figure 1: Transverse section of CT showing defect in between external oblique (EO) and internal oblique (IO).

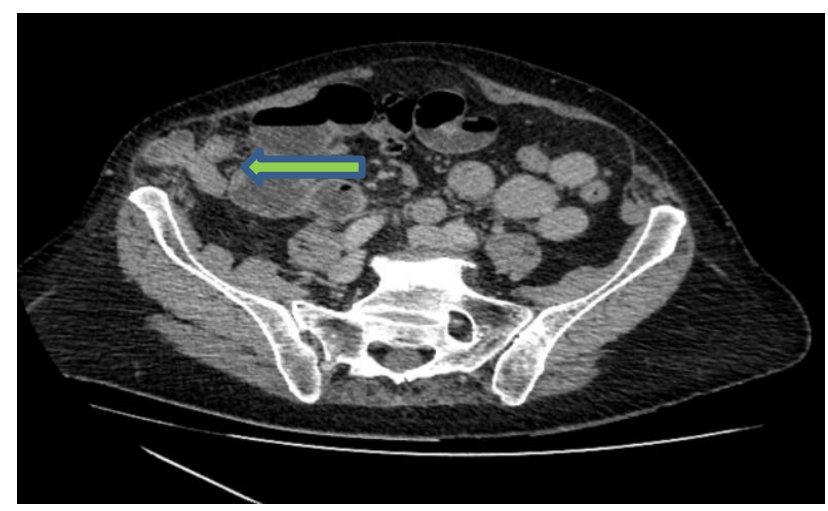

Figure 2: Cross section of CT scan showing Richter's type of hernia.

She was taken to theatre immediately and lateral transverse incision was made under general anaesthesia (GA). Keeping in mind regarding the differential diagnosis of peritonitic or ischemic bowel. Intra operative picture shows intraparietal hernia with Richter's type of hernia, Sac contains bowel with no necrosis or gangrene, proximal bowel viable, no signs of bowel ischemia, rest of the small bowel is healthy (Figure 3 and 4). Bowel pushed inside, sac sutured and pushed inside. Preperitoneal mesh repair done with ventral patch. Abdominal wall layers closed and hence the abdomen was closed and the procedure was completed.

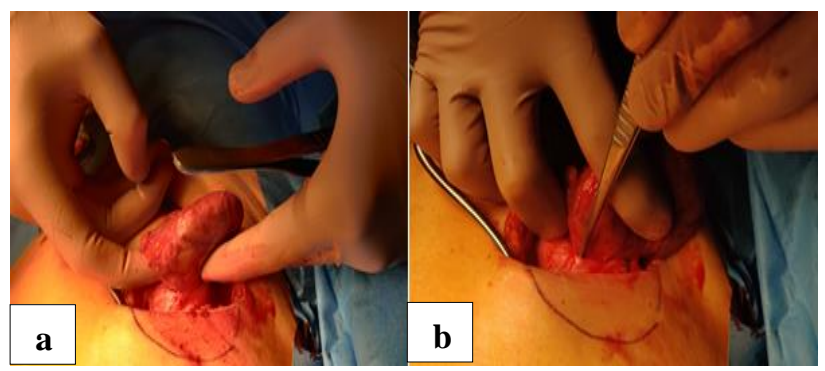

Figure 3: (a) and (b) sac with bowel contents which is intraparietal (between EO and IO).

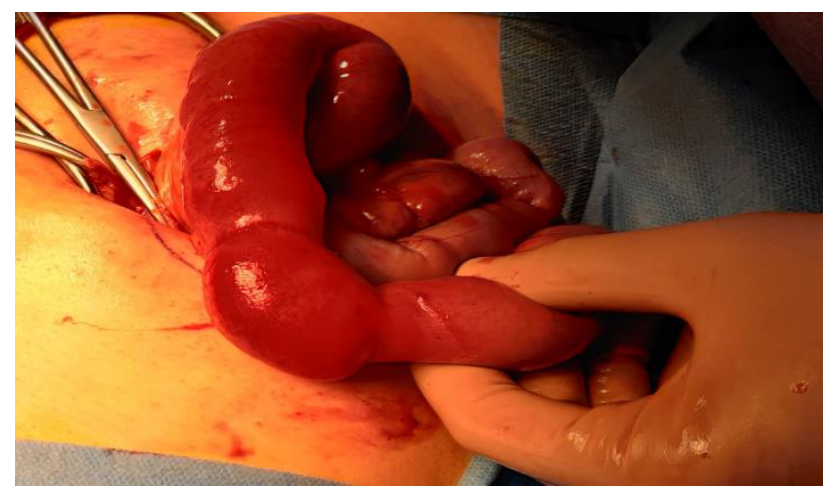

Figure 4: Richters type of hernia with viable bowel contents after opening the sac.

\section{Outcomes and follow ups}

The clinical outcome of obstructed $\mathrm{SH}$ is highly variable depending on contents and duration of the obstruction and also associated with its co morbidities. The patient was shifted to surgical ward and was started on antibiotics and analgesia. She did considerably well intraoperatively and the post-operative period was unremarkable and hence the patient as discharged and followed up after 6-8 weeks' time.

\section{REVIEW OF LITERATURE}

We conducted a MEDLINE literature search using the MeSH terms "spigelian" and "Richter's hernia". We came across 6 publications of Richter-type spigelian hernias, all of which were thoroughly reviewed. Other articles were identified concerning spigelian Richter's hernias from the references of the articles reviewed.

Of the articles generated from MEDLINE, all cases documenting Richter-type $\mathrm{SH}$ were selected and 
thoroughly reviewed $(\mathrm{N}=6)$ (Table 3$)$. In addition, several articles concerning $\mathrm{SH}$ were selected for relevance and were reviewed completely.

Table 1: Risk factors for Spigelian hernia.

\begin{tabular}{|ll|}
\hline Categories & Risk factors \\
\hline Intra-abdominal & $\begin{array}{l}\text { Chronic constipation, ascites, } \\
\text { traumas, and previous surgery }\end{array}$ \\
\hline Respitatory & $\begin{array}{l}\text { Chronic obstructive pulmonary } \\
\text { disease }\end{array}$ \\
\hline General & $\begin{array}{l}\text { Obesity, rapid weight loss, } \\
\text { multiple pregnancies }\end{array}$ \\
\hline
\end{tabular}

Table 2: Size of the hernial defect and its treatment approach.

\begin{tabular}{|ll|}
\hline $\begin{array}{l}\text { Size of hernial defect } \\
\text { no peritoneal } \\
\text { components }\end{array}$ & Approach \\
\hline Moderate-sized defect & $\begin{array}{l}\text { Open conventional } \\
\text { approach }\end{array}$ \\
\hline Larger hernias & $\begin{array}{l}\text { Oppen repair due to the } \\
\text { approassible need for abdominal } \\
\text { possill reconstruction }\end{array}$ \\
\hline
\end{tabular}

Table 3: Summary of published cases reports of Richter-type of Spigelian hernias and its managements.

\begin{tabular}{|c|c|c|c|c|c|}
\hline Reference & Age/ gender & Presentation & Site of hernia & Diagnosis & Treatment \\
\hline $\operatorname{Carr} \mathbf{J}^{17}$ & $83 / \mathrm{F}$ & $\begin{array}{l}\text { RLQ abdominal } \\
\text { pain and vomiting }\end{array}$ & Left & CT scan & $\begin{array}{l}\text { Laparoscopic ventral hernia } \\
\text { repair }\end{array}$ \\
\hline $\begin{array}{l}\text { Parambath A N } \\
\text { et al }{ }^{18}\end{array}$ & $62 / \mathrm{M}$ & $\begin{array}{l}\text { abdominal pain and } \\
\text { vomiting }\end{array}$ & Right & CT scan & Open repair with mesh \\
\hline Foster D et al ${ }^{19}$ & $27 / \mathrm{M}$ & $\begin{array}{l}\text { Signs of } \\
\text { strangulation }\end{array}$ & Left & CT scan & $\begin{array}{l}\text { Laparoscopic repair with } \\
\text { mini laparotomy Small } \\
\text { bowel resection with mesh }\end{array}$ \\
\hline Hiller et al $^{20}$ & $82 / \mathrm{F}$ & $\begin{array}{l}\text { RLQ abdominal } \\
\text { pain with vomiting }\end{array}$ & Right & US scan & $\begin{array}{l}\text { Small bowel resection with } \\
\text { no mesh }\end{array}$ \\
\hline $\begin{array}{l}\text { Raveenthiran et } \\
\text { al }^{21}\end{array}$ & $75 / \mathrm{M}$ & $\begin{array}{l}\text { LLQ abdominal } \\
\text { pain and vomiting }\end{array}$ & Left & US scan & $\begin{array}{l}\text { Small bowel resection with } \\
\text { no mesh }\end{array}$ \\
\hline Naylor 22 & & & & & $\begin{array}{l}\text { Wedge cecectomy and } \\
\text { simple herniorraphy }\end{array}$ \\
\hline
\end{tabular}

\section{DISCUSSION}

Spigelian hernia is the protrusion of preperitoneal fat, peritoneal sac, or organ (s) through an abnormal opening either congenital or acquired defect in the aponeurosis, which is located in the between the semilunar line laterally and the rectus abdominis muscle medially. SH was named after Adriaan van Spieghel, a Belgian anatomist who described the semilunar line. But the hernia was first described by Klinkosch in $1764 .{ }^{5}$ It is otherwise called as lateral ventral hernias or hernia of the semilunar line, or hernias through the conjointed tendons. The defect is mostly adjacent to the semilunar line but is more commonly found at the arcuate line because of the absence of a posterior rectus sheath.

\section{Etiology and risk factors}

SH occurs frequently between $4^{\text {th }}$ decade and $7^{\text {th }}$ decade of life with the female predominance. Some of the predisposing factors that causes $\mathrm{SH}$ are discussed in Table 1. These factors causes rise in intra-abdominal pressure and also weakness of the abdominal wall. ${ }^{6}$

Patients usually present with swelling and palpable mass in the mid-to-lower abdomen and it is lateral to the rectus muscle just above the ASIS which is often associated with sharp pain or tenderness at this site. The abdominal pain varies from $31 \%$ to $86 \%$ of cases. ${ }^{7}$ The swelling lies posterior to external oblique muscle. In supine position, the hernia reduces on its own with mild discomfort. There may be signs of intestinal obstruction which is the most common presenting complaint like abdominal pain, distension, vomiting along with obstipation. In our patient we had all these complaints with signs of intestinal obstruction. The incidence rate of incarceration of $\mathrm{SH}$ was reported to be around $24-27 \%$ and that of strangulation which varies between 2 and 14\%.8, ${ }^{8,9}$ The content of $\mathrm{SH}$ usually varies from small bowel or omentum, but the large bowel, stomach, gallbladder to Meckel's diverticulum, ovary, testis, leiomyoma of the uterus, and even urinary bladder were also been reported in the hernia sacs. ${ }^{10}$ The content of the sac in our patient was jejunum with Richter's type. Even the Richter's type of hernia in SH has also been reported.

\section{Investigations}

Clinically, the diagnosis of $\mathrm{SH}$ is difficult and challenging to make, as patient often presents with signs of obstruction with no obvious mechanical cause. Imaging techniques are preferred options to diagnosis using X ray abdomen, US, CT scan or MRI depending on the resources available. The ultrasound (US) scan is the first line imaging in the 
investigations as per the literature but it is restricted due to the availability of the scan in out of hours. So the preferred scan was to take CT scan which has the sensitivity of $100 \%$ and positive predictive value of $100 \%$. It gives us a detailed idea of the anatomy, contents of the sac and also tells us the ischemia of the bowel. Unless the CT is inconclusive MRI scan doesn't a major role. In all the imaging there will be visible fascial deficit.

\section{Treatment}

The surgical approaches vary from conventional open hernia repair with primary sutures or meshplasty to laparoscopic approach which is becoming quite famous now a days. In our patient we performed conventional open hernia repair with preperitoneal mesh repair. In today's era, laparoscopic approaches is being performed with $100 \%$ diagnostic accuracy. It can be either extraperitoneal or intra peritoneal approaches. In 1992, Carter and Mizes performed first intra-abdominal laparoscopic repair of Spigelian hernia where they used suturing techniques without mesh to close the defect. ${ }^{13}$ Following that there have been many reports of successful management of SH by laparoscopic approach. MorenoEgea et al and his colleagues performed a first daycare procedure in 1999. ${ }^{11}$ Another study by Moreno-Egea et al in 2002, showed no significant difference in conventional or laparoscopic surgeries in epidemiological and clinical factors but laparoscopic approach has advantage in terms of morbidity and hospital stay which was statistically significant. ${ }^{11}$

Webber et al describes laparo $\neg$ scopic Spigelian hernial repair in $107 \mathrm{SH}$, Out of which 65 operations were done open and 42 were laparoscopic. ${ }^{3}$ Out of 42 patients where 4 different laparoscopic approaches were used, e.g. 19 totally extraperitoneal (TEP), 11 intra-peritoneal onlay mesh (IPOM), and 7 transabdominal partial extraperitoneal (TAPE) and open technique. Along with that a hernia staging system was introduced in this study. For example in hernias with no peritoneal composition, an open conventional approach is advocated as the defect may not be visible through laparoscopic approach. A moderatesized defect can be repaired open or laparoscopically, and primary suture repair of small defects is recommended. Larger hernias with significant distortion of the abdominal wall are recommended for open repair due to the possible need for abdominal wall reconstruction (Table 2).

Even single-incision laparoscopic (SIL) SH repair was also performed in 2013 by Peterko et al with no complications or recurrence but the follow-up period was only 2 months. ${ }^{14}$ Another case series of $8 \mathrm{SH}$ repairs using similar technique with totally extraperitoneal (SILTEP) technique was reported by Tran et al with 1 complication of haematoma requiring incision and drainage with no recurrences over a 18-month follow-up. ${ }^{15}$

A systemic review by Barnes et al used in the laparoscopic repair techniques of $\mathrm{SH} .50$ articles were reviewed for the final reporting. ${ }^{16}$ A total of 237 SHs were repaired by various techniques were included in this study. Among which, IPOM technique was the most popular repair method with minimal complications and recurrences reported in all other techniques. Similar studies by Nagarsheth et al compared with mesh and without mesh repair in incidentally found $\mathrm{SH}$ during laparoscopic cholecystectomy for acute cholecystitis and indentified an increase in recurrence rate in no mesh repair. ${ }^{4}$ There were few more studies which states IPOM was the most commonly used technique in spite of increased risk of developing adhesions between the mesh and peritoneal contents. Transabdominal preperitoneal (TAPP) was the second most used technique, with TEP being the least used..$^{3,8}$

\section{CONCLUSION}

SHs are rare type of ventral abdominal hernias with uncommon presentations sometimes asymptomatic but usually diagnosed with complications. They differ from other ventral hernias which do not pass through all layers of the abdominal wall, leaving a cavity and potential space for seroma collection. It can be diagnosed by radiological imaging mainly with CT scan. Laparoscopic approach is becoming popular now, but the surgical techniques varies depends on patient characteristics, surgeon's preference and experience.

\section{Funding: No funding sources \\ Conflict of interest: None declared \\ Ethical approval: Not required}

\section{REFERENCES}

1. Pinna LC, Maria P, Panagiotis CG, Alessandro GF, Alberto P. Spigelian hernia: a series of cases and literature review. Annali Italiani di Chirurgia. 2016;87:306-11.

2. Cinar H, Polat AK, Caglayan K, Ozbalci GS, Topgül HK, Polat C. Spigelian hernia: our experience and review of the literature. Ann Ital Chir. 2013;84:64953.

3. Webber V, Low C, Skipworth RJE, Kumar S, de Beaux AC, Tulloh B. Contemporary thoughts on the manage $\neg$ ment of Spigelian hernia. Hernia. 2017;21:355-61.

4. Nagarsheth KH, Nickloes T, Mancini G, Solla JA. Lap $\neg$ aroscopic repair of incidentally found Spigelian hernia. JSLS. 2011;15:81-5.

5. Klinkosch JT. Programma Quo Divisionem Herniarum, Novumque Herniae Ventralis Specium Proponit. Rotterdam: Benam. 1764.

6. Campanelli G, Pettinari D, Nicolosi FM, Avesani EC. Spigelian hernia. Hernia. 2005;9:3-5.

7. Bastidas JG, Khan AR, LeBlanc KA. Spigelian hernia as a cause of small bowel obstruction. Southern Med J. 2010;103:567-9.

8. Moreno-Egea A, Campillo-Soto Á, Morales-Cuenca G. Which should be the gold standard laparoscopic 
tech $\neg$ nique for handling Spigelian hernias? Surg Endosc. 2015;29:856-62.

9. Leff DR, Hassell J, Sufi P, Heath D. Emergency and elective laparoscopic repair of Spigelian hernias: two case reports and a review of the literature. Surg Lapa $\neg$ rosc Endosc Percutan Tec. 2009;19:152-5.

10. Skandalakis PN, Zoras O, Skandalakis JE, Mirilas P. Spigelia hernia: surgical anatomy, embryology, and technique of repair. Am Surg. 2006;72:42-8.

11. Moreno-Egea A, Torralba JA, Aguayo JL. Totally ex $\neg$ traperitoneal laparoscopic repair of Spigelian hernia. Eur J Coeliosurg. 1999;32:83-4.

12. Moreno-Egea A, Carrasco L, Girela E, Martín JG, Aguayo JL, Canteras M. Open vs laparoscopic repair of Spigelian hernia: a prospective randomized trial. Arch Surg. 2002;137:1266-8.

13. Carter JE, Mizes C. Laparoscopic diagnosis and repair of Spigelian hernia: Report of case and technique. Am J Obstet Gynecol. 1992;167:77-8.

14. Peterko AC, Kirac I, Cugura JF, Bekavac-Beslin M: Single incision laparoscopic Spigelian hernia repair an approach with standard instrumentarium. Acta Clin Croat. 2013;52:383-6.

15. Tran H, Tran K, Zajkowska M, Lam V, Hawthorne WJ. Single-incision laparoscopic repair of Spigelian hernia. JSLS. 2015;19.

16. Barnes TG, McWhinnie DL. Laparoscopic Spigelian hernia repair: a systematic review. Surg Laparosc En $\neg$ dosc Percutan Tech. 2016;26:265-70.
17. Carr J. Image of the month — quiz case. Arch Surg. 2007;142:799.

18. Parambath AN, Hajaji K, Al Hilil SA. Spigelian hernia with Richter-type herniation of the ileum: a rare cause of right iliac fossa pain mimicking acute appendicitis. J Emerg Med Trauma Acute Care. 2012;7.

19. Foster D, Nagarajan S, Panait L. Richter-type Spigelian hernia: A case report and review of the literature. Int J Surg Case Rep. 2015;6:160-2.

20. Hiller N, Alberton Y, Shapira Y, Hadas-Halpern I. Richter's hernia strangulated in a Spigelian hernia: ultrasonic diagnosis. J Clin Ultrasound. 1994;22:5035.

21. Raveenthiran V, Pitchumani S. Richter's hernia in Spigelian hernia. Indian J Gastroenterol off J Indian Soc Gastroenterol. 2000;19:36-7.

22. Naylor J. Combination of Spigelian and Richter's hernias: a case report. Am Surg. 1978;44:750-2.

Cite this article as: Ravi $\mathrm{P}$, Rajebhosale R, Husain $\mathrm{N}$. An unusual presentation and management of incarcerated Richter's type of Spigelian hernia - a rare case report and review of literature. Int Surg J 2020;7:3856-60. 